DOI: $10.20472 /$ IAC.2019.049.021

\title{
HARTWIG HÜMME
}

University of Potsdam, Germany

\section{EFFECTS OF SOCIAL ORIGIN AND OWN ABILITIES ON INCOME DEVELOPMENT - NEW FINDINGS FROM GERMANY}

\begin{abstract}
:
The relationship between social origin and future income has been the subject of numerous studies and debates in economics and sociology. It has been proven that there is a strong link between social origin, educational attainment, and social destination in terms of economic success. However, there is still widespread disagreement as to whether social origin has an influence on later children income. The results of previous studies are not unequivocal in their findings and contradict each other in the effects observed. It's also still completely unclear whether there are differences between the genders.
\end{abstract}

However, studies based on correlations between siblings or twins show that there is a strong correlation between social origin and economic success achieved in later working life. But these studies only show that there are effects and not which mechanisms are responsible for them. But it is very important to understand these mechanisms as they are responsible for the persistence of social inequality and gender differences.

In this study, I take up the proposal by Bukodi \& Goldthorpe (2013) to decompose social origin into its main factors parental class, status and education in order to examine the distinct effect on income over the life course. To do this, I use the data from the German LifE-Study, one of the longest running longitudinal studies in the German regions following the life courses of $N=1.359$ individuals from the ages of 12 to 45. Different linear regressions and linear structural equation models show that the three factors of social origin have different effects on income. These effects also differ between age 35 and age 45 of the analyzed individuals and largely between men and women. For women not only their own education is responsible for the returns to education, it's also the social background in which they grew up.

\section{Keywords:}

Social origin, income, sociology

JEL Classification: $125,124,121$ 